\title{
DESCRIPTION OF THE PUMPING ENGINE AT THE NEWCASTLE WATER WORKS.
}

BY Mr. ROBERT MORRISON, OF NEWCASTLE-ON-TYNE.

The Pumping Engine forming the subject of the present paper was constructed by the writer for the Whittle Dean Water Works, and has been erected near Benwell, a village about two miles west of Newcastle-on-Tyne, where filter beds and an extensive pure water basin have likewise been recently constructed. About ten miles west of Benwell, at Welton, there are eight extensive collecting and settling reservoirs, called the Whittle Dean reservoirs, containing at their ordinary high water level 600 million gallons of water, but capable of holding a much greater quantity. The average low water level of these reservoirs is 360 feet above the high water line in the Tyne, and the water is conducted into the towns of Newcastle and Gateshead through a 24 inch cast iron main by gravitation. Owing to the extension of these towns up the banks of the Tyne, considerable portions of them are above the level to which the water will flow direct from Welton. To supply these districts an engine and reservoir were constructed some years ago at Gateshead; which afterwards proving insufficient through the increased demand for water, the engine here described was erected, and can now at all times supply the highest districts by gravitation alone with an unlimited quantity of water.

Down the bank opposite Benwell, at about the level of high water in the Tyne, runs the 24 inch Welton main, from which a 10 inch branch has been led up the hill side a distance of 2240 feet to the filter beds already mentioned, which are placed at a level of 246 feet above high water line in the Tyne. The water passing from the beds to the pure water basin is conducted to the engine suction pipe, and is driven through another 10 inch main 3850 feet long into a second recently formed reservoir at the top of the bank at High Benwell, 
412 feet above high water in the Tyne, from which the town is supplied through a 10 inch main. When it is not required to pass the water through the filtering beds or pure water basin, the 10 inch branch from the Welton main delivers the water direct into a well 20 feet deep, whence it is pumped by the engine as before to the second reservoir up the hill. The height from the bottom of the well to the end of the delivery pipe in High Benwell reservoir is 182 feet, which is the height the engine has been lifting during the experiments ; for the depth of water in the well has generally been about equal to the depth of water in the high reservoir.

The pumping engine, which was erected twelve months ago, is a horizontal high-pressure expansive and non-condensing engine, working direct a double-acting pump, and coupled to a crank and flywheel. Figs. 1 and 2, Plates 13 and 14, are a longitudinal section and sectional plan of the engine and pump: Figs. 3 and 4, Plate 14, are transverse sections through the pump and through the steam cylinder.

The steam cylinder $A$ is 26 inches diameter and 4 feet stroke; and the pump B, which is worked from the same piston rod, is $11 \frac{1}{2}$ inches diameter. A crosshead is keyed upon the piston rod and guided by a cylindrical slide $\mathrm{C}$ on each side, working on round guide rods DD carried by brackets from the bed plate; and the connecting $\operatorname{rod} \mathrm{E}$ is coupled to the crosshead close to the piston $\operatorname{rod} \mathrm{F}$, which is lengthened sufficiently to allow the crank to clear the end of the pump B. The crosshead is made solid in one piece with the cylindrical guide on the side to which the connecting rod is attached, and the other side is made with a socket and keyed. Each guide $\mathbf{C}$ is provided with two set screws to allow of tightening up the brasses as they wear. The flywheel $G$ is 16 feet diameter and $5 \frac{1}{2}$ tons weight. The pump B is double-acting, and has a solid piston fitted with cupped leathers facing both ways, with a brass piece between them to preserve the leathers from being cut. The pump valves $\mathrm{H}$, shown enlarged in Figs. 5 and 6, Plate 14, are rectangular butterfly valves of india-rubber $1 \frac{1}{4}$ inch thick, beating on $\frac{1}{2}$ inch bars, with 1 inch spaces; the total area of opening in each valve seat is 112 square inches. The suction valves open from a chamber $I$ in the bed plate to which the suction pipe $\mathrm{K}$ leads from the well; and a back flap valve 
of india-rubber is fixed at the extremity of the pipe $K$ at the bottom of the well, 20 feet below the pump suction valves. The delivery valves are exactly similar to the suction valves and immediately over them, and they are connected by a horizontal pipe $L$ parallel to the pump $B$, from which the delivery pipe $M$ leads off proceeding direct to the main. A branch is carried off obliquely from the main to the air vessel, which is situated outside the building and is 3 feet diameter and 12 feet high. Two small air vessels $\mathrm{NN}$ are also fixed on the top of the pump B, immediately over the two delivery valves.

The steam cylinder is fitted with a separate expansion slide $O$, working on the back of the ordinary slide valve $P$. This arrangement is shown enlarged in Figs. 7 and 8, Plate 15. Both slides are worked by fixed eccentrics, but the expansion is made variable by means of a slotted link $R$, vibrating on a centre fixed to the bed plate, and permanently connected to the rod of the expansion slide $O$, which is attached to the centre of the link, the eccentric rod being connected to a sliding block worked up and down the slot by means of a screw, which can be readily adjusted whilst the engine is at work. There is an index on the side of the link to show the degree of cut-off. The exhaust steam is discharged into a cistern $S$ cast in the foundation plate, into which the cold feed water is injected through a perforated pipe $T$; by this means the feed water is heated and is then pumped from the cistern into the boiler. A glass gauge on the side of the cistern indicates the level of the water, as it is desirable that there should not be more than 3 inches depth in the cistern.

As the eccentrics are fixtures on the flywheel shaft and the rods permanently connected to the slide valves for the sake of simplicity and durability of construction, a special arrangement is provided for starting the engine by means of a two-way cock U, Fig. 7, attached at the bottom of the steam chest and connected by small branch pipes to both steam ports, by which the steam can be turned into either port beyond the valve and the engine readily started. There are three Cornish boilers with single flues, having the fire in the flue; the boilers are 28 feet long and 4 feet 9 inches diameter, and the flues 3 feet diameter; but only two boilers at a time are used for working the engine. The firedoors are arranged to admit any quantity of air, 
and regulated in such a manner as to be under the control of the engineer; the result is perfect combustion and the entire absence of smoke with the Benwell pit coal.

The steam is maintained at $60 \mathrm{lbs}$. per square inch above the atmosphere, and the engine is usually worked with the steam cut off at $\frac{1}{5}$ th of the stroke. A specimen of the indicator diagram is shown in Fig. 9, Plate 15. The main slide $P$ having always exactly the same motion, whatever be the degree of expansion, the opening of the exhaust and the amount of compression are constant. The usual speed of the engine is 24 revolutions per minute, or 192 feet per minute speed of piston; but it has been worked up to 40 revolutions, or 320 feet per minute of the piston. The pressure of water upon the pumps as indicated by a pressure gauge is $80 \mathrm{lbs}$. per square inch when standing, and rises to a mean of about $95 \mathrm{lbs}$. per square inch whilst working, equivalent to $18 \cdot 6 \mathrm{lbs}$. per square inch "effective pressure on the steam piston or 57 horse power effective. Taking the coals consumed for 3 months, the consumption is $30 \mathrm{cwts}$. per day of 12 hours, including lighting fires $8 \mathrm{cc}$, or $5 \mathrm{lbs}$. of coals per effective horse power per hour, and 4 lbs. per indicated horse power per hour. It will thus be seen that the consumption of coals is not much more than if this engine had been a condensing one, whilst the first cost of the engine and building is much less, and the smooth and steady motion of the machine is much in its favour when compared with the beam engines.

The Champman regretted that Mr. Morrison was mavoidably prevented from being present as expected. He observed that an independent starting apparatus was now in general use for large engines working expansively, having become requisite as a convenient mode of readily starting the engine. He enquired whether the starting cock described in the paper was used also as a blow-off cock. 
The Secretary replied that it was only a two-way cock for starting the engine, and was found a simple and convenient plan for starting the engine with the expansion gear set to any required point of cut-off; but the sliding block could be readily adjusted while the engine was working, as the speed was not too great to prevent this. He had seen the engine at work, and had seen the indicator diagram taken; the engine worked very steadily and smoothly.

The Charman remarked that the india-rubber pump valves shown in the drawings appeared to be fixed in the centre by the guard, so as always to beat on the grid in the same place; and he feared they would consequently be found to cut after working for some time, although india-rubber valves wore well when sufficient play was allowed for them to beat in a different place each time. The india-rubber valves used in marine engine air pumps were made circular and left free to turn on the centre spindle, to allow of shifting their position on the grids; and he thought it would be desirable to allow some play in the rectangular valves by fixing the india-rubber flap with slot holes, in order to diminish the wear by allowing it to shift a little on its seat. He enquired how long these india-rubber valves had been found to stand when used for water works purposes.

Mr. H. Marten said he had used Mr. Hosking's india-rubber ball valves for water works pumping engines under a heavy pressure, and found they answered well, as the balls dropped in a different position into the seating at each time of closing, so that the wear was distributed equally over the entire surface; some of the ball valves had now been at work for three or four years at the Hull Water Works, proving highly satisfactory in durability and working. He had also used Mr. Hosking's ring valves, having flat rings of india-rubber beating on circular gratings; in these the rings were left loose and free to turn, but appeared to beat always on the same part; they stood well, but he had not yet had long experience of their working. He had not tried rectangular butterfly valves of india-rubber, like those shown in the drawing; but feared that with a heavy pressure of water the indiarubber would be liable to wear out, and might be forced down into the openings of the grid so much as to lose its elasticity, unless it could be made proportionately thick for a heary pressure. He thought a 
circular valve would be much better than the rectangular form, so as to allow the valve to turn and beat in different parts.

Mr. J. Fernie observed that it would be very adrantageous for a general comparison to be made between the heavy beam engines previously employed for pumping and the lighter description of directacting engines that were now coming into general use, both as to cost of construction per horse power and consumption of fuel in working: the subject had been before the Institution several times, and descriptions had been given of large beam pumping engines, which were necessarily cumbersome and expensive in construction; while the present paper and others described a lighter and cheaper class of engine. It was desirable to ascertain what had been actually done with each construction of engine, as there was now a close competition between the heary and light descriptions of engines; and he hoped the comparison between them would be taken up by some of the members, as the subject of a future paper.

Mr. A. B. Cochrane thought it was an excellent suggestion, and was sure one of the members might be found to take up the subject in the manner suggested, well qualified by experience in connexion with direct-acting engines for pumping, and who had taken much interest in the introduction of smaller engines in place of large and heavy beam engines.

Mr. W. Smith observed that the engine described in the paper presented a useful example of a simple construction of pumping engine, though there did not appear to him any novel features in it; he thought a different arrangement of the expansion gear would have been preferable, and that the hand screw in the vibrating link would be inconvenient for altering the degree of expansion unless the engine was working slowly. He would have been glad also to hear some further particulars of the working of the engine, as to economy of results compared with ordinary beam engines used at water works; and considered it would be very advantageous for such comparisons to be carried out as completely as possible.

Mr. J. Fernie observed that the object desired in papers brought before the Institution was not novelty alone, but it was of perhaps greater importance to obtain authentic records of works successfully 
executed, and indicator diagrams from engines, with correct particulars of consumption of fuel and work performed; he thought it was very important to encourage such communications, and the particulars of failures also proved sometimes of as great practical value as successful results.

The Charrman considered it was desirable to have as full details as possible of the comparative working and economy of all engines that were brought before the Institution; and expressed a wish for some further particulars of the comparative working of the engine described in the paper: he hoped some member would carry out fully the comparison suggested between direct-acting and beam pumping engines, in respect of weight, cost, economy of working, and other particulars, as it would prove of great value and interest. He proposed a vote of thanks to Mr. Morrison for his paper, which was passed.

The following Paper was then read:- 
Fig. 1. Longitudinal Section of Engine and Pump.

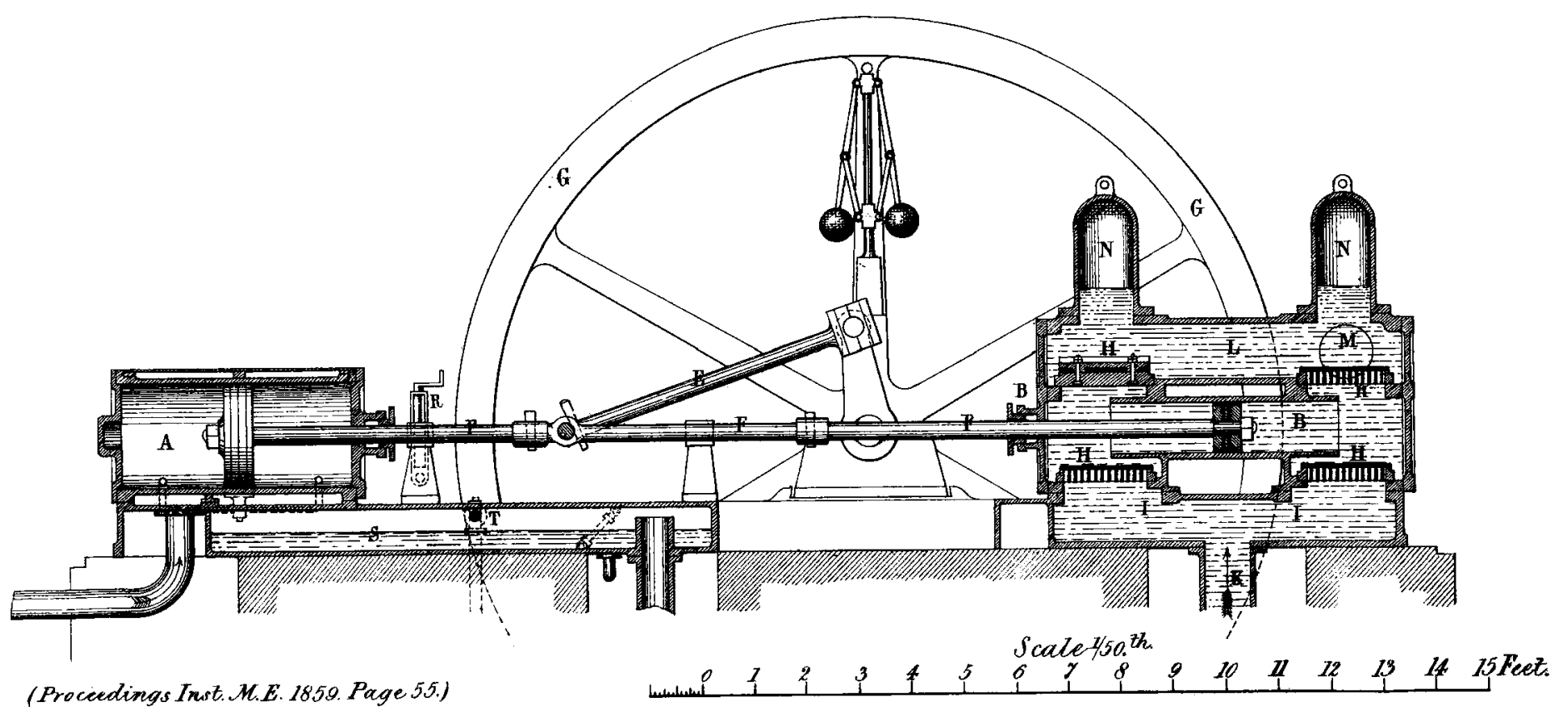


NEWCASTLE PUMPINC ENGINE.

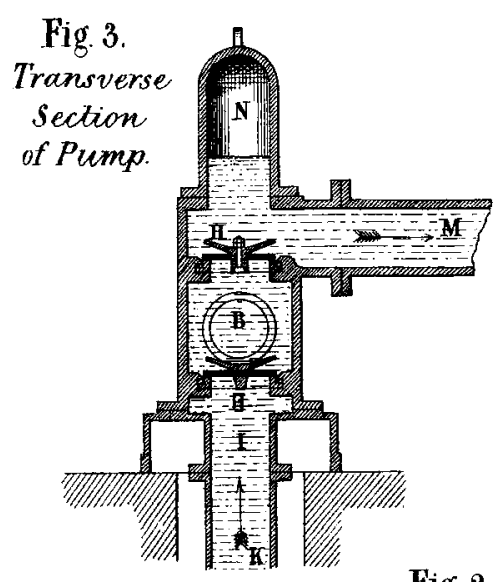

Fig. 5.

Transverse Section of Pump Valve.

D

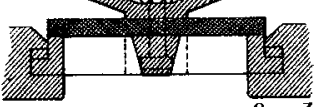

Scate ${ }^{2} / 15^{\text {th }}$

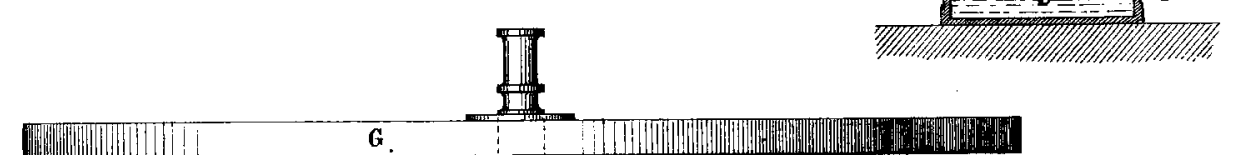

Fig. 6.

Longitudinal Section, of Pump Valve.

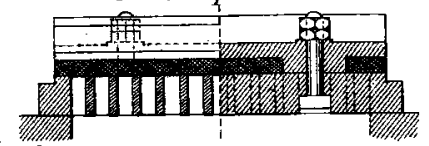
5.th
Fig.4. Transverse Section of sleam Gylinder.

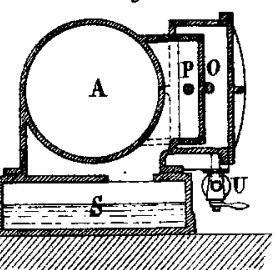

(Proceedings.Inst. M.E. 1859. Page 55)

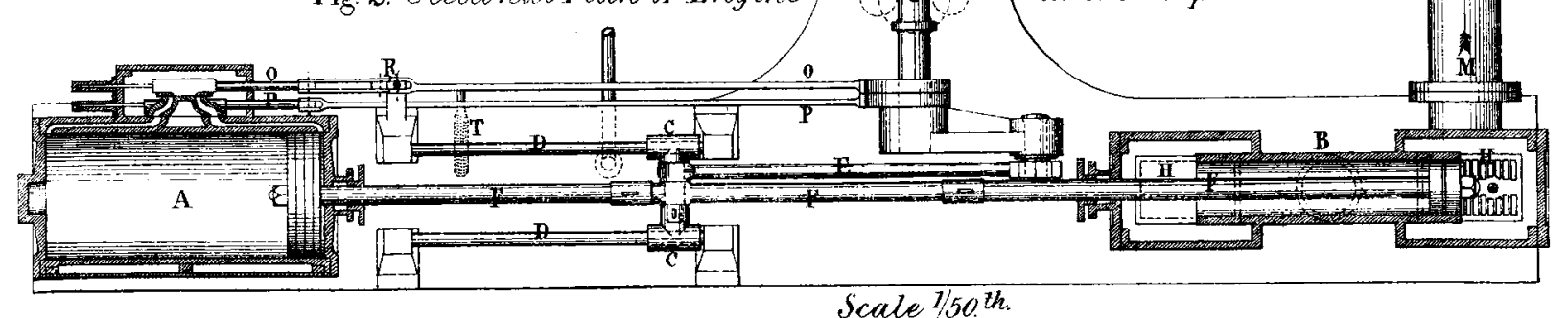

Downloaded from pme.sagepub.com at WEST VIRGINA UNIV on June 5, 2016 
NEWCASTLE PUMPING ENGINE.

Plate 15.

Fig.7. Elevation of Eirpamsion Gent ruth Totors.

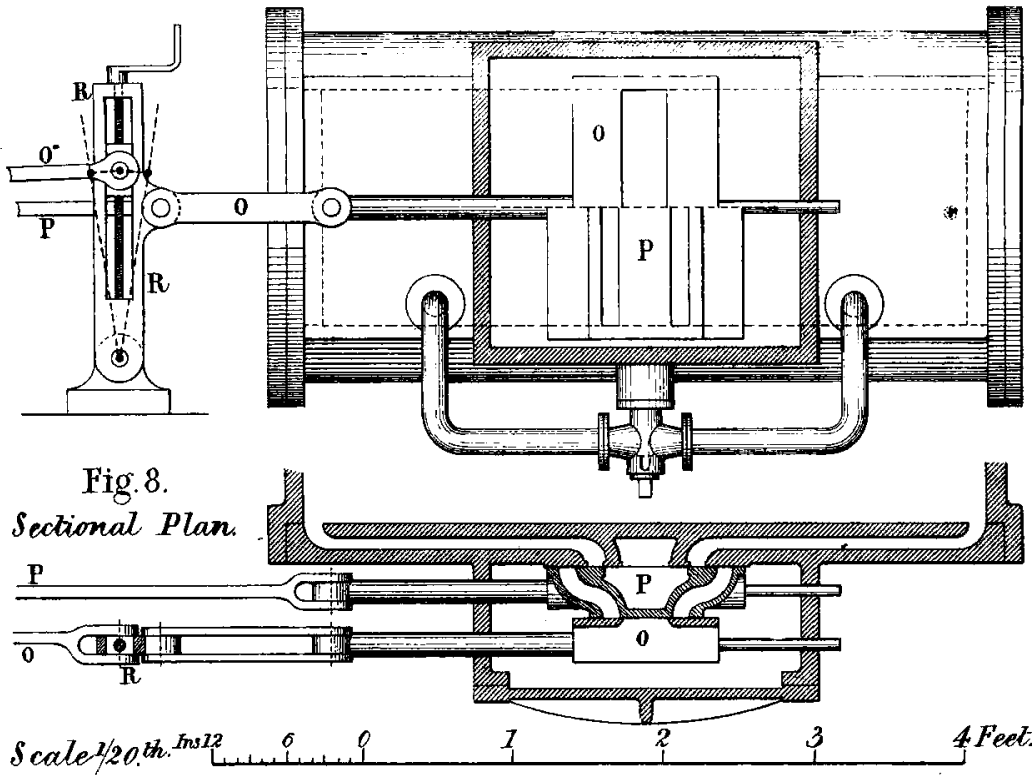

Lbs. Fig. 9. Indicator Diagram.

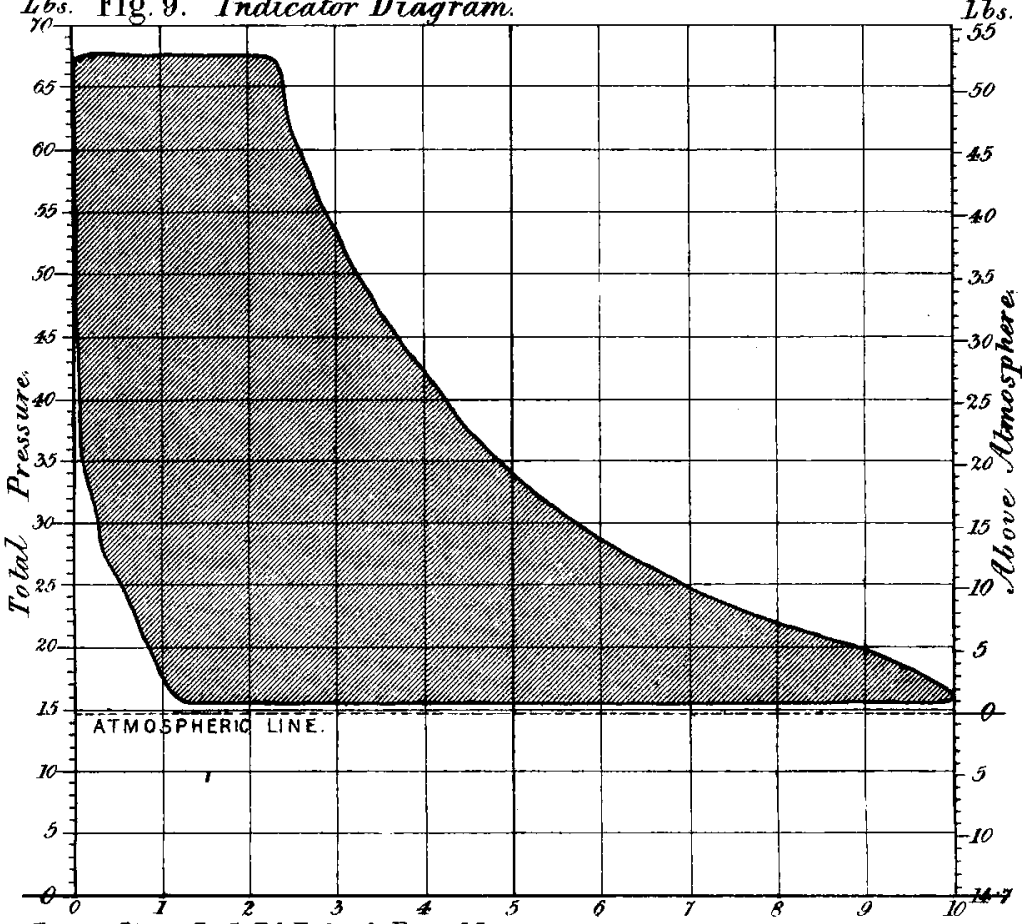

(Proceedings Inst.7T.E. 1859. Prge 55.)

Downloaded from pme.sagepub.com at WEST VIRGINA UNIV on June 5, 2016 